\title{
The social configuration of labour market divides: an across- and within- country analysis in Germany, Belgium and Italy
}

\author{
Nadja Doerflinger ${ }^{1}$, Valeria Pulignano and Martin Lukac
}

\begin{abstract}
The article uncovers and analyses insecurity-based dividing lines and their social configurations in the German, Belgian and Italian labour markets in 2015 based on latent class analysis applied to European Union Labour Force Survey data. Conversely to the dual vision of 'insider-outsider' approaches, our findings illustrate the existence of five distinctive labour market groups or segments across countries with similar social configurations. We explain this by referring to the social embeddedness of the investigated countries' national regulatory systems, which generate different degrees of inclusiveness for different groups of workers. This adds to ongoing debates on connecting micro- and macro-levels of analysis, as labour market segmentation as macro phenomenon is studied based on its micro-foundations (i.e. terms and conditions of employment relationships), and the interlinkages between national regulatory systems and social categories are used to explain the findings.
\end{abstract}

Keywords: Social divides, segmentation, insecurity, employment, latent class analysis

\section{Introduction}

Although segmentation and inequality are persistent problems in European labour markets, we lack knowledge about where labour market divides are located, and which groups of workers are on which side of the divide(s). Sociological studies on inequality (e.g. Tilly, 1998) propose focusing on workplaces as the locus where employment conditions are organized, and consequently, dividing lines are generated. Recent employment research calls for connecting macro-level analyses of institutional change and micro-level analyses of the dynamics underpinning these changes as resulting from the social relations at work (Brandl and Lehr, 2018; Pulignano and Doerflinger, 2018a). Studies within the tradition of institutional segmentation theory investigate divides as embedded in country-specific regulatory systems, affecting the form that segmentation takes (Beynon et al., 2002; Osterman, 1994; Rubery, 1978). In accordance, segmentation is framed within the capital-labour rather than the workerworker relationship, as divides result from the diversity in the extent to which employment conditions - embedded in national regulatory systems - are regulated around decent standards. Although regulatory systems should ensure decent working conditions, inequality could result from inclusive or exclusive models of eligibility (Grimshaw et al., 2018). For instance, countries' social protection systems may discriminate workers by employment contract or continuity (Grimshaw et al., 2018). Hence, interlinkages between employment and social protection systems may feature varying degrees of inclusiveness. In this vein, inclusive regulatory systems are not sufficient, as regulation promoting encompassing employment practices is equally important (Rubery et al., 2016).

This article builds on institutional segmentation theory (e.g. Osterman, 1994; Rubery, 1978;) which acknowledges the interlinkages between employment and social protection systems, tied to labour market regulation and the degree of inclusiveness of employment practices when examining labour market divides. We define these divides as segmentation lines between secure and insecure workers and consider them as grounded in the terms and conditions of workers' employment relationships embedded in national regulatory systems. Therefore, we build on existing research claiming that insecurity causes major dividing lines in contemporary labour markets (e.g. Eichhorst et

\footnotetext{
${ }^{1}$ Corresponding author: Nadja Doerflinger, KU Leuven, Centre for Sociological Research, Parkstraat 45 bus 3601, 3000 Leuven, Belgium; nadja.doerflinger@kuleuven.be
} 
al., 2016; Rubery and Piasna, 2016), yet, it is not clear where these dividing lines are located, and whether they are identical across countries. Therefore, the article aims at uncovering the locations of dividing lines and examines whether (and why) they are (not) similar across countries.

We use latent class (LC) analysis based on the European Union Labour Force Survey (EU-LFS) to uncover and analyse divides between different groups of workers in Germany, Belgium and Italy in 2015. We expect different kinds of labour market divides in the investigated countries (i.e. Germany, Belgium and Italy) due to specificities in national regulatory systems. Our country choice thus follows the logic of contextualized comparisons (Locke and Thelen, 1995) as we compare countries that are generally considered similar aiming at unveiling differences between them. We also explore and illustrate which social categories can be found in the identified segments within and across countries. We call these segmentation lines 'social divides'. By positioning the study of segmentation within national regulatory systems which intersect with social categories in labour markets, we provide a nuanced analysis of labour market segmentation.

The article demonstrates that the investigated countries' regulatory systems are not politically or 'socially' neutral but contested as they reflect actors' actions (i.e. law, agreements, policy) and behaviours (Granovetter, 1992), affecting the extent to which inclusiveness is guaranteed for different groups of workers. In so doing, the article adds to ongoing debates on connecting micro- and macrolevels of analysis, as it incorporates the micro-foundations (i.e. terms and conditions of employment relationships) of labour market segmentation as macro phenomenon, and uses the interlinkages between national regulatory settings and social categories as explanatory variables.

The paper is structured as follows. In the first part we present our approach towards 'social divides' by explaining its analytical relevance, core assumptions and implications. Having explained aspects of methods, data and operationalization, the following part explains the main results of our LC analysis, highlighting the social divides. These findings are explained in the light of national regulatory systems. Lastly, the conclusion particularly stresses implications for further research.

\section{An approach to 'social divides' in labour markets}

Early theories of labour market segmentation developed along an institutional and a Marxian trajectory. Accordingly, institutional theories consider labour markets as divided into primary and secondary segments (Doeringer and Piore, 1971). In contrast, Marxian theories view workforce divisions as reinforced by belonging to particular social categories (e.g. women or migrants frequently work in secondary segment jobs). Specifically, capitalists create workforce divisions on purpose to disrupt the formation of class solidarity and possible resistance. Therefore, the persistence of a casual workforce is a reflection of these considerations, which are not directly related to the secondary segment's productivity potential (Rubery, 1978). Despite differences between institutional and Marxian segmentation theories, both emphasize that labour markets should be analysed by studying the characteristics of jobs in the context in which people are employed. Thus, the workplace is the level at which a general analytical framework for understanding the structure and functioning of the labour market develops (Rubery, 2007). In contrast to solely using individual productivity to explain the existence of secondary segment workers, institutional segmentation theory highlights the role of workplace practices as embedded in national regulatory systems in creating segmentation (for a summary, see Rubery and Piasna, 2016).

Recent literature on segmentation particularly stems from the dualization debate rooted in political science (e.g. Emmenegger et al., 2012; Rueda, 2014). Dualization scholars engage in understanding differences between labour market insiders (i.e. the employed) and outsiders (i.e. the unemployed and/or those in atypical employment), and their implications, for instance related to the voting behaviour of these groups (e.g. Marx and Picot, 2013). This debate is strongly characterized by a binary or dual vision of the labour market, differentiating secure and insecure/vulnerable labour market positions (Palier and Thelen, 2010). Although some dualization research critically engages with the limitations linked to dual configurations (e.g. Häusermann and Schwander, 2013), the binary vision generally makes sense for them, as it enables revealing broad socio-structural patterns of divides and preferences. Yet, from a sociological perspective, there is an essential limitation to this approach. Studying only two pre-defined groups means that the presumably high level of within-group variation 
remains hidden. This is because the two groups are treated as homogeneous social categories despite the fact that employment research has highlighted more fragmented configurations (e.g. Blossfeld and Mayer, 1988; Yoon and Chung, 2016). Relatedly, the variable contract type, which is often used to distinguish insiders and outsiders, may not be the best measure due to changes across and within contractual groups in recent years. Employment literature highlights the changing nature of standard and non-standard employment, as well as heterogeneity within these categories (e.g. Stone and Arthurs, 2013; Lautsch, 2012).

We follow studies arguing that a plurality of segmentation patterns exists rather than dualization between two groups (e.g. Blossfeld and Mayer, 1988; Fernandes-Macias, 2012). We assume that these fragmented configurations differ across countries due to specificities of national regulatory systems. Therefore, we introduce the analytical approach towards 'social divides', which aims at advancing knowledge in three ways.

First, it empirically investigates patterns of segmentation instead of studying assumed divides between (two) pre-defined labour market groups. Earlier studies (e.g. Biegert, 2014) often used predefined groups (i.e. insiders and outsiders) and examined the nature and/or extent of differences between them, for instance regarding income or employment stability. In so doing, there is a risk of not uncovering the main dividing lines within and across labour markets because there is no empirical assessment of the causes of segmentation, based on which the groups on the side(s) of the divide(s) can be identified. Moreover, within-group variation remains hidden when studying pre-defined groups. Yoon and Chung (2016) provide an exception as their study empirically assesses segmentation patterns in Britain, identifying a third segment between insiders and outsiders.

Second, we advance knowledge on cross-national segmentation patterns by comparing Germany, Belgium and Italy. This is because such patterns are likely to vary across countries reflecting differences in socio-political, -economic and -cultural institutions as well as regulatory systems. Yet, knowledge on cross-national segmentation patterns is scarce, which could be related to the difficulty of comparing institutions across countries (Locke and Thelen, 1995). Numerous studies highlight possible cross-national differences and the need to explore them (for a review, see Davidsson and Naczyk, 2009), however, there are only a few qualitative (e.g. Palier and Thelen, 2010) and quantitative (e.g. Biegert, 2014) studies doing so.

Third, we aim at uncovering the social configuration of the identified divides since labour markets are characterized by the "unequal distribution of possibilities of access of some groups to certain material and symbolic conditions, or to "social goods"' (Kreckel, 1980: 528). This is in line with social reproduction theory, stressing the heterogeneity of the workforce, not only in terms of employment contracts or skills but also regarding the position workers occupy in the labour market's social structure (Fagan and O'Reilly, 1998). Thus, identifying the social groups with different degrees of access to 'social goods' across and within countries enables analysing the 'social divides'.

Workplaces are central contexts in which segmentation is created as working conditions are largely regulated at this level, which is embedded in national regulatory systems (Beynon et al., 2002). It is at this level where the micro-foundations for labour market segmentation as macro-level phenomenon are laid (Pulignano and Doerflinger, 2018a). We therefore consider the conditions underpinning a worker's employment relationship as key when examining social divides because they determine a worker's degree of (in-)security. In accordance with manifold contributions (e.g. Eichhorst et al., 2016 or Rubery and Piasna, 2016), segmentation nowadays particularly reflects divides between workers on secure versus insecure jobs.

\section{The employment relationship and the insecurity-based divide}

Debates on the progressive shift from standard to non-standard employment relationships (e.g. Stone and Arthurs, 2013) highlight that different degrees of (in-)security could cause segmentation. However, the standard employment relationship may not be a good proxy for the degree of (in-)security as various studies highlight that workers on standard contracts could suffer from insecurity (Doerflinger, 2016; Lautsch, 2002; Lewchuk, 2017; Weil, 2014). Building upon such studies, we argue that instead of solely looking at the form of the employment relationship (i.e. contract type) we need to study its terms and conditions to assess divides between secure and insecure jobs. In line with Gallie et al. (2017), we use 
a broad definition of insecurity which is not only linked to the risk of job loss. Instead, we claim that the concept encompasses the terms and conditions of employment relationships unfolding at the workplace. This has three advantages. First, it allows for a nuanced analysis of insecurity by acknowledging its multidimensional and relational nature, as insecurity relates to different characteristics of the employment relationship. Second, it entails capturing variation within contractual groups related to other features than contract type which affects the degree of (in-)security. Third, the aforementioned variation can be linked to job-related and personal characteristics, which makes us identify the 'social' divides.

We use Rodgers' (1989) distinction between four dimensions of insecurity (i.e. temporal, organizational, economic, social); we argue that they are inherently related to the terms and conditions of the employment relationship. The first dimension is temporal insecurity referring to the continuity of employment. In accordance, insecure jobs are characterized by short time horizons and/or the possible risk of job loss. We use two indicators to measure this dimension: 1) the type of employment contract someone holds is integrated in the analysis as temporary contracts provide work within a clearly defined (and possibly short) time horizon in contrast to permanent contracts; 2) the number of weekly working hours (i.e. full hours versus part-time hours). Although some part-time jobs could come along with relative stability, others - particularly in private services - may not only be involuntary, but also instable as the availability of work may fluctuate in accordance with demand (to capture the possible interlinkages between working hours and sectors, sector based on NACE codes is used as so-called external variable in the analysis). Thus, such jobs may not be 'continuously available' in line with Rodgers, which may make them temporally insecure.

The second dimension is organizational insecurity which refers to the degree of control a worker has over the work process. In accordance, the less a worker is able to control his/her working conditions, wages, and the pace of work, the more insecure a job tends to be. This kind of control is implicitly linked to hierarchies in companies as well as the degree of standardization of jobs. Higher level positions (less standardized) tend to come along with more control, whereas lower level positions (more standardized) are often characterized by lower control. We use two variables to capture the organizational insecurity dimension. On the one hand, supervisory responsibility is used as a proxy for control when measuring labour market segmentation. On the other hand, we use occupation based on ISCO-codes as external variable, as there is an implicit link between occupation and levels of control. For instance, we assume control levels (and the degree of standardization) to be rather low in occupational groups as 'elementary occupations' or 'plant and machine operators', whereas 'managers' and 'professionals' tend to have more control over their working conditions, wages and pace of work.

The third dimension - i.e. economic insecurity - refers to wages. Low-wage jobs can be associated with insecurity, as they may come along with difficulties to make ends meets and (in-work) poverty. The employment relationship defines the wage that an employer pays to the employee in exchange for the work performed, but this wage level may of course be influenced by national and collectively agreed minimum levels. We include wage deciles to cover the economic insecuritydimension. Furthermore, we include if someone has a second job as external variable because this can be associated with difficulties to make ends meet.

Finally, social insecurity generally relates to workers' extent of protection against issues like discrimination or unfair dismissal as well as protection in the sense of social security benefits. Such protections are normally given through national laws or collective agreements. Therefore, it is not per se the employment relationships' terms and conditions entitling a worker to certain protections, but rather the fact that someone has an employment contract. Yet, depending on the national regulatory system, entitlements may differ in accordance with types of employment contracts. Considering the social insecurity dimension in our quantitative analysis would imply studying a country's entire population to find variation. Yet, we solely focus on employed people, who are generally entitled to protections based on their employment contracts although variations in the level of entitlements may exist. Furthermore, the article primarily focuses on the micro-level (i.e. social divides between employees) and not the macro-level (i.e. country-level social protections).

\section{Data and methods}


To uncover social divides in the German, Belgian and Italian labour markets, we use LC analysis applied to EU-LFS data. EU-LFS is an annual cross-sectional survey curated by Eurostat, focused on Europe's working population. Data is collected in 28 EU Member States, two candidate countries, and three countries of the European Free Trade Association. Our analyses focus on the employed population because we consider insecurity as grounded in the terms and conditions of employment. It would not make sense to include the unemployed due to the absence of an employment relationship; furthermore, the self-employed are excluded for the same reason.

To investigate insecurity-based labour market divides, we use LC analysis (Hagenaars and McCutcheon, 2002; McCutcheon, 1987) - a model-based clustering method that creates groups of observations that are similar on a number of characteristics. In other words, LC analysis allows us to identify labour market segments based on a set of variables linked to insecurity (see Table 1). Having identified the segments, we subsequently investigate their population using various socio-demographic and job-related variables (see Table 1). Generally, the use of LC analysis is based on theoretical deliberation that observed indicator variables (i.e. variables linked to insecurity) are statistically associated due to an unobserved common factor rather than being causally related (McCutcheon, 2002). LC analysis thus offers scope to investigate patterns of labour market segmentation that are not directly observable.

We used a bias-adjusted three-step approach (Bakk et al., 2013; Vermunt, 2010); first we created a LC model based on the aforementioned variables linked to insecurity, then we assigned subjects into the extracted labour market segments, and in the last step, we analysed associations between labour market segments and various socio-demographic and job-related variables (i.e. external variables). Data was weighted by the yearly weighting factor supplied by EU-LFS. More information on the quantitative methodology, the selected multi-group latent class model as well as model fit criteria can be found in appendix 1 and 2 and in Lukac et al. (2019).

The items used for operationalizing insecurity in line with Rodgers (1989) are illustrated in Table 1. Insecurity-related variables are used to build up the measurement model; and sociodemographic and jobs-related variables are utilized to investigate the identified segments' populations in a subsequent step. It is important to underline that this subsequent analysis does not affect the formation of segments.

[Table 1 about here]

\section{Uncovering social divides in the German, Belgian and Italian labour markets}

Based on the theoretically grounded, explanatory LC analysis applied to the German, Belgian and Italian data, we uncover five distinct labour market segments, which demonstrates that there is substantively more fragmentation and complexity than assumed by binary approaches. Table 2 and 3 illustrate the identified segments' profiles. First, the group which we label 'standard workers 1' covers $12 \%$ of the investigated workforce. Almost everybody in this group has a permanent, full-time contract (more than 96\%), nobody has supervisory responsibilities, and wage levels tend to be medium or high. Second, $31 \%$ of the workforce belongs to 'standard workers 2'. This group is similar to the former, but there are differences in the share of workers on temporary contracts (9\%), working part-time $(21 \%)$, and having supervisory responsibilities $(22 \%)$. These two groups of standard workers face low to medium levels of temporal and economic insecurity, and medium to high levels of organizational insecurity. Third, the group labelled as 'managers' covers $27 \%$ of the investigated workforce. Managers have permanent, full-time contracts (more than 97\%), about $61 \%$ has supervisory responsibilities and approximately $82 \%$ earn high wages. Hence, the 'managerial workforce' faces low levels of temporal, organizational, and economic insecurity. Fourth, $26 \%$ of the investigated workforce are "part-time workers', as almost $70 \%$ of group members work part-time hours. More than $80 \%$ have permanent contracts, $91 \%$ do not have supervisory responsibilities and wages tend to be low for the entire group. Finally, the group of 'temps' covers $4 \%$ of the investigated workforce. Almost everyone in this group 
has temporary contracts and works full hours. Hardly anyone has supervisory responsibilities and about $80 \%$ of temps earn low wages. Part-time workers and temps generally face high levels of temporal, economic and organizational insecurity.

There is a clear pattern regarding the social categories belonging to the identified segments. The two groups of standard workers are relatively balanced in their social configuration. In contrast, managers are mostly older men with high education levels, whereas part-time workers and temps tend to be young with low to medium education levels. The majority of part-time workers are female, and temps are predominantly male. Furthermore, the probability of being a non-national is the highest in the two aforementioned segments. Therefore, the identified divides reflect categorical divisions between different social groups, which the labour market as social institution seems to reproduce.

[Table 2 about here]

With regard to occupations (see Table 3), the identified patterns are hardly surprising. Occupational groups featuring relatively standardized work (i.e. elementary occupations, sales and service workers) with low degrees of control are particularly found among part-time workers and temps. In contrast, those in hardly standardized occupations (i.e. professionals and managers) with high levels of control belong to the managerial workforce. Occupations featuring medium levels of standardization (e.g. plant, machine operators, and assemblers, craft and trade workers, technicians and associate professions, clerical support workers) are likely to be part of the standard workforce. With regard to the other external variables (i.e. sector, firm size, second job), no clear patterns evolve.

[Table 3 about here]

Figure 1 displays group sizes in the investigated countries. Belgium has the least fragmented labour market, with three broad groups, i.e. standard workers 1 (47\%), part-time workers $(27 \%)$ and managers (24\%). Standard workers 1 are not present in Belgium, and the share of temps is tiny (less than $1 \%)$. In Italy, there are four broad groups, namely part-time workers (29\%), standard workers 1 (29\%), managers (23\%), and standard workers $2(16 \%)$. In contrast, temps only cover $3 \%$ of the investigated workforce. In Germany, there are three broad and two small labour market groups, i.e. standard workers 2 (39\%), managers (29\%), and part-time workers (23\%), as well as temps (5\%), and standard workers $1(4 \%)$.

[Figure 1 about here]

\section{Explaining social divides: the role of national regulatory systems}

Following institutional segmentation theory, the characteristics of national regulatory systems provide explanations for the uncovered social divides. Calculating $\mathrm{R}^{2}$ values ${ }^{1}$ (see Table 4) sheds light on national variation, as these values indicate how well the extracted latent classes (i.e. labour market segments) predict the indicators (i.e. variables linked to insecurity) in the model. The closer the $\mathrm{R}^{2}$ value to 1 , the stronger the connection between the indicator and the latent measurement of segmentation. In the pooled model comprising all countries, wages have the highest explanatory power for insecurity-based divides, followed by working hours, contract type and supervisory responsibilities. Although the combination of indicators shapes insecurity, our analysis demonstrates that economic insecurity is the most important dimension, followed by temporal and organizational insecurity. Table 4 also highlights national specificities; while wages and working hours are important everywhere, contract type matters more in Germany compared to Belgium, and supervisory responsibilities more in Italy than in Germany and Belgium. Thus, social divides are not caused equally across countries; there are differences in accordance with regulatory systems, which intersect with social categories.

The extent to which working hours matter depends on the regulation of full-time and part-time work, and the gap between them. A wide range of studies has investigated the part-time work penalty, 
highlighting gaps in wages and social security contributions, access to training and promotion, and the difficulty of moving back into full working hours (e.g. Eurofound, 2013; Jepsen et al., 2005; Russo and Hassink, 2005). While the share of part-time work is similar across the investigated countries $(22.2 \%$ in Germany, $18.5 \%$ in Italy, 16.4\% in Belgium according to 2017 OECD data), its regulation differs, with implications for the level of insecurity accompanying this form of work.

\section{[Table 4 about here]}

In Germany, where working hours matter the most, normal and marginal part-time work need to be distinguished. While normal part-time workers enjoy the same entitlements as full-time employees relative to the lower amount of working hours, marginal part-time work underlies lower social security contributions (see $\S 8$ SGB IV). This has two effects: First, it causes higher (social) insecurity for the workers, particularly in the long-run, as contributing to the pension fund is voluntary. Second, lower contributions make hiring marginal part-time workers cheaper for firms. Therefore, they may have an incentive to create such (insecure) jobs (Stuart et al., 1998). In contrast, marginal part-time work does not exist in Belgium and Italy, where equal provisions relative to working hours are formalized by law, and an inferior treatment of part-time workers is generally forbidden (Italy: legal decree 81, June 2015; Belgium: various legal sources, see http://www.werk.belgie.be/detailA_Z.aspx?id=1056).

Working hours are intertwined with social categories, as a large proportion of part-time workers in the investigated countries are female. The aforementioned part-time penalty is interlinked with the fact that women frequently work in private services and in smaller firms (which is also confirmed by our data), entailing weaker collective regulation in many countries (Rubery and Fagan, 1995). While legal regulation like national minimum wages sets universal standards, collective regulation at the sector and/or company level is likely to create differences across industries and establishments, which may cause particular disadvantages for women because of their greater presence in weakly regulated sectors and small establishments. This comes along with wage differences between men and women, as wage levels in private services tend to be lower than in traditional 'male' manufacturing sectors. Furthermore, women may be more vulnerable to lower wages because traditional role models consider them as secondary earner in the household, which is reflected in pay levels (Bendl et al., 2012). While the average unadjusted gender pay gap in Europe amounted to $16.2 \%$ in 2016, it was $21.5 \%$ in Germany, but only $6.1 \%$ in Belgium and 5.3\% in Italy (Eurostat, 2018), indicating huge gender wage differentials in Germany.

This gap also reflects specificities of these countries' bargaining systems. In particular, decentralization and declining bargaining coverage rates (56\% in 2016, according to OECD data) in Germany's industry bargaining system have contributed to generating inequality, particularly between traditional manufacturing sectors and services (e.g. Pulignano and Doerflinger, 2018b). In contrast, Belgium's and Italy's bargaining systems remain more centralized with collective bargaining coverage rates of 96\% (2016) and 80\% (2015) respectively, though recent reforms in Italy (i.e. Renzi's Jobs Act) foster decentralization (Pinelli et al., 2017). The wage dispersion in Italy is higher compared to Belgium, which could get more pronounced resulting from recent reforms stimulating low-paid employment at the margins of the labour market. Yet, there is more pay equality across sectors in Belgium and Italy compared to Germany, where collective regulation may largely reflect the labour market's gender structure, setting lower standards for women (Rubery and Fagan, 1995) and causing higher levels of temporal and economic insecurity for them.

Furthermore, our analysis reveals differences with regard to contract type across countries. Contract type has very limited explanatory power in Belgium because regulation is equally strong for permanent and temporary contracts. Equal pay and working conditions are stipulated by law, and if there are differences regarding voluntary fringe benefits, strong local unions often bargain additional agreements to close the gap between permanent and temporary employees (Pulignano and Doerflinger, 2013). In contrast, regulation of permanent and temporary contracts strongly differs in Germany, leading to gaps in wages and working conditions, particularly between permanent and temporary agency workers (who are mostly employed on fixed-term contracts). Equal provisions do not necessarily apply due to an opening clause, giving priority to collective regulation. As the existing collective agreements for the agency work sector set lower standards compared to most other sectors, inequalities between permanent and agency workers are generated (see Pulignano and Doerflinger, 2013). Italy is situated in 
between Germany and Belgium regarding the importance of contract type. While equal provisions used to apply in Italy, recent reforms (i.e. Fornero Act in 2012, Renzi's Jobs Act in 2015) have reduced dismissal protection for permanent workers while increasing protection for temporary workers. At the same time, temporary employment has been facilitated, e.g. by lifting the obligation to provide a valid reason for using it (Eurofound, 2015). Since we analyse data from 2015, the effects of recent reforms may not yet be reflected in our analyses.

Following our results, the majority of temps are young people. Temporary contracts are often a way to enter the labour market, and respective regulatory provisions exist in all investigated countries. Specifically, in Belgium 'labour market entry' is one of the six motives allowing companies to use temporary agency work which usually includes fixed-term contracts for the workers (Håkansson et al., 2017). Similarly, the German labour law allows labour market entrants to be given temporary contracts without the normally required valid reason for it. Relatedly, apprentices are hired on temporary contracts, too. Since Germany features the comparably highest number of temps - a group mostly made up by young men in manufacturing - we suppose this group to contain many apprentices. Similarly, temporary apprenticeship contracts for young people also exist in Italy, as well as another form of employment contract (i.e. intermittent labour contract) for workers aged 24 years or younger. Generally, our data supports the well-documented idea (e.g. Passaretta and Wolbers, 2016) that temporary contracts function as stepping stone to other forms of employment. This is because more than $98 \%$ of temps belong to the youngest age cohort; older age cohorts are hardly present among this sub-group, which is a strong indication for a trajectory starting with temporary contracts which are subsequently upgraded over time. The fact that many temps are young workers or apprentices also explains their rather low wages. Overall, our analyses demonstrate that the importance of the contract type variable is interlinked with the regulatory gap between permanent and temporary contracts. Where this gap exists (i.e. Germany), the variable contributes to shaping social divides. Our results also emphasize the intersection between contract type and age, as particularly young workers tend to be employed on temporary contracts.

Organizational insecurity contributes the least to shaping social divides in Germany, Belgium and Italy. Although higher levels of control over working conditions, wages and the pace of work may come along with higher security, the economic and temporal dimensions of insecurity may outweigh this.

Overall, the presented results show the interconnections between national regulatory settings and social categories shaping social divides in the investigated labour markets. Our analysis highlights the social embeddedness of regulatory systems; they are shaped and reshaped by actors, and this influences their degree of inclusiveness, which in turn creates the observed insecurity-based labour market divisions. Thus, actors generate the micro-foundations of social (macro-) phenomena (Pulignano and Doerflinger, 2018a). In sum, our analysis yields two major results. First, it demonstrates that segmentation research can benefit from connecting micro- and macro-levels. Specifically, we used micro-level variables (i.e. terms and conditions of the employment relationship) to uncover dividing lines in the German, Belgian and Italian labour markets, and studied them as grounded in national regulatory settings. To make sense of the uncovered divides, we particularly examined the interlinkages between national regulatory settings and social categories, which provide explanations for the observed social divides. Second, it sheds light on the existence of complex socio-economic configurations in the investigated labour markets. Those tend to be more fragmented than generally assumed; therefore, instead of approaching the topic of segmentation as solely linked to insiders and outsiders, our research suggests that it is more accurate to talk about different degrees of insider- and outsiderness. Those degrees result from interactions between the terms of conditions of a worker's employment relationship, his/her social characteristics and regulatory settings. As regulatory settings differ, our analysis revealed variation across three investigated labour markets which are often considered as similar (e.g. Hall and Soskice, 2001). Therefore, our findings are in line with recent research advocating for departing from broad categories such as liberal and coordinated market economies and rather exploring dynamics and the possibly resulting variations within categories or country clusters (Thelen, 2014).

\section{Conclusion}


This article analysed social divides in the German, Belgian, and Italian labour markets. Our results highlight the existence of five segments across countries, with Belgium's configuration being less fragmented compared to Italy and Germany. While the two identified groups of standard workers are relatively balanced in terms of age, gender and education, managers are predominantly highly-educated, older men. In contrast, part-time workers tend to be (young) women and temps young men, with low to medium education levels. Therefore, the identified social divides reflect categorical divisions in society.

Our analyses generate three essential implications for further research. First, there is a certain level of convergence, as similar labour market groups could be identified across countries despite differences in national regulatory systems. Yet, these differences are key to explain the uncovered divides, which are not functionally equivalent across countries. For example, our results demonstrate that contract type is less important than wages and working hours in shaping insecurity-based divides. Previous research has often attributed security to permanent contracts, yet, our results demonstrate that other indicators linked to the terms and conditions of the employment relationship may more strongly contribute to generating (in-)security. Moreover, the importance of contract type differs across the investigated countries, reflecting specificities of regulatory systems. Future research should therefore not treat indicators as functionally equivalent across countries and rather follow the idea of contextualized comparisons (Locke and Thelen, 1995) when selecting cases and analysing research results. Relatedly, one should be cautious when comparatively studying the same pre-defined groups across countries, as for instance the atypical workforce in Germany has a very different labour market position compared to its Belgian counterpart.

Second, the identified social configurations reflect categorical inequalities - particularly along the lines of gender, age, education level and ethnicity. These categories intersect, creating additional labour market disadvantages. Our results suggest that such intersections through social categories may contribute to revealing the processes through which inequalities are perpetuated in society. Alike existing intersectionality research (e.g. McBride et al., 2015), our results confirm that a combined understanding of for example gendered and age-based work processes could lead to more comprehensive explanations of the production of social disadvantages in contemporary labour markets.

Third, our analyses stress the existence of insecurity-based labour market divides, which are intertwined with regulatory systems and social categories. Segmentation along the dimensions of temporal, economic and organizational insecurity particularly disadvantages women, migrants, young and lowly-educated workers, and is deeply rooted in sectoral and national regulatory systems. Therefore, our study highlights that drivers of segmentation could (co-)exist at various (regulatory) levels including national/sectoral and individual. This stresses the relevance to develop novel theoretical and methodological approaches enabling to investigate social divides at these different levels, and particularly to study their interaction. 


\section{Notes}

1) We use Goodman-Kruskal tau-b coefficients as R2 statistic (Southwood, 1974), indicating how well an indicator is explained by the latent variable, which is similar to conventional interpretations of the variance explained in analysis of variance and to item communalities in factor analysis (Vermunt and Magidson, 2005). The values are provided in LatentGOLD 5.1 output.

\section{References}

Bakk Z, Tekle FB and Vermunt JK (2013) Estimating the Association between Latent Class Membership and External Variables Using Bias-adjusted Three-step Approaches. Sociological Methodology 43(1): 272-311.

Bendl R, Hanappi-Egger E and Hofmann R (2012) Diversität und Diversitätsmanagement. Wien: facultas.

Beynon H, Grimshaw D, Rubery J and Ward K (2002) Managing employment change. The new realities of work. Oxford: Oxford University Press.

Biegert T (2014) On the outside looking in? Transitions out of non-employment in the United Kingdom and Germany. Journal of European Social Policy 24(1): 3-18.

Blossfeld HP and Mayer KU (1988) Labor market segmentation in the Federal Republic of Germany: an empirical study of segmentation theories from a life course perspective. European Sociological Review 4(2): 123-140.

Brandl B and Lehr A (2018) A problem of embeddedness: A micro-theoretical model of trade union action and interaction in Europe. Employee Relations 40(3): 500-514.

Davidsson J and Naczyk M (2009) The Ins and Outs of Dualisation: A Literature Review. Working Papers on the Reconciliation of Work and Welfare in Europe REC-WP 02/2009.

Doerflinger N (2016) Different worlds of work? A study on labour market regulatory institutions and contingent work in Belgium and Germany. Unpublished PhD thesis: University of Leuven.

Doeringer P and Piore M (1971) Internal labor markets and manpower analysis. Lexington: Heath and Company.

Eichhorst W, Marx P and Wehner C (2016) Labor market reforms in Europe: Towards more flexicure labour markets? IZA Discussion Paper No. 9863.

Emmenegger P, Häusermann S, Palier B and Seeleib-Kaiser M (2012) The age of dualization. The changing face of inequality in deindustrializing societies. Oxford: Oxford University Press.

Eurofound (2013) Part-time work in Europe. Dublin: Eurofound.

Eurofound (2015) Italy: Changes to fixed-term contracts. Retrieved from https://www.eurofound.europa.eu/publications/article/2015/italy-changes-to-fixed-term-contracts.

Eurostat (2018) Gender pay gap statistics. Retrieved from http://ec.europa.eu/eurostat/statisticsexplained/index.php/Gender_pay_gap_statistics.

Fagan C and O'Reilly J (1998) Conceptualising part-time work: the value of an integrated comparative perspective. In O'Reilly J and Fagan C (eds.) Part-time prospects: an international comparison of part-time work in Europe, North America and the Pacific Rim. London: Routledge, 1-32.

Fernandez-Macias E (2012) Job polarization in Europe? Changes in the employment structure and job quality, 1995-2007. Work and Occupations 39(2): 157-182. 
Gallie D, Felstead A, Green F and Inanc H (2017) The hidden face of job insecurity. Work, Employment and Society 31(1): 36-53.

Granovetter, M (1992) Institutions as social constructions: a framework for analysis. Acta Sociologica 35(1): 3-11.

Grimshaw D, Cartwright J, Keizer A and Rubery J (2018) Market exposure and the labour process: the contradictory dynamics in managing subcontracted services work. Work, Employment and Society doi:10.1177/0950017018759206.

Hagenaars JA and McCutcheon A (2002) Applied latent class analysis. Cambridge: Cambridge University Press.

Håkansson K, Pulignano V, Isidorsson T and Doerflinger N (2017) Explaining job insecurity for temporary agency workers: A comparison between Sweden and Belgium. Economic and Industrial Democracy doi:10.1177/0143831X17707824.

Hall P and Soskice D (2001) Varieties of capitalism: the institutional foundations of comparative advantage. Oxford: Oxford University Press.

Häusermann S and Schwander H (2013) Who is in and who is out? Proposing a risk-based operationalisation of insiders and outsiders. Journal of European Social Policy 23(3): 248-269.

Jepsen M, O'Dorchai S, Plasman R and Rycx F (2005) The wage penalty induced by part-time work: the case of Belgium. Brussels Economic Review 48(1/2): 73-94.

Kreckel R (1980) Unequal opportunity structure and labour market segmentation. Sociology 14(4): $525-$ 550.

Lautsch B (2002) Uncovering and explaining variance on the features and outcomes of contingent work. ILR Review 56(1): 23-43.

Lewchuk W (2017) Precarious jobs: Where are they, and how do they affect well-being? The Economic and Labour Relations Review 28(3): 402-419.

Locke R and Thelen K (1995) Apples and oranges revisited: contextualized comparisons and the study of comparative labor politics. Politics \& Society 23(3): 337-367.

Lukac M, Doerflinger, N and Pulignano P (2019) Developing a cross-national comparative framework for studying labour market segmentation: measurement equivalence with latent class analysis. Social Indicators Research doi:10.1007/s11205-019-02101-3.

Marx P and Picot G (2013) The party preferences of atypical workers in Germany. Journal of European Social Policy 23(2): 164-178.

McBride A, Hebson G and Holgate J (2015) Intersectionality: are we taking enough notice in the field of work and employment relations. Work, Employment and Society 29(2): 331-341.

McCutcheon A (1987) Latent class analysis. London: SAGE.

McCutcheon A (2002) Basic concepts and procedures in single- and multi-group latent class analysis. In Hagenaars $\mathbf{J}$ and McCutcheon A (eds.) Applied latent class analysis. Cambridge: Cambridge University Press, 56-88.

OECD (2018) Part-time employment statistics. Retrieved from https://data.oecd.org/emp/part-timeemployment-rate.htm.

Osterman P (1994) How common is workplace transformation and who adopts it? ILR Review 47(2): 173-188.

Palier B and Thelen K (2010) Institutionalizing dualism: complementarities and change in France and Germany. Politics \& Society 38(1): 119-148. 
Passaretta G and Wolbers M (2016) Temporary employment at labour market entry in Europe: Labour market dualism, transitions to secure employment and upward mobility. Economic and Industrial Democracy doi:10.1177/0143831X16652946.

Pinelli D, Torre R, Pace L, Cassio L and Arpaia A (2017). The Recent Reform of the Labour Market in Italy: a Review. European Economy Discussion Paper 72, retrieved from https://ec.europa.eu/info/sites/info/files/economy-finance/dp072 en.pdf.

Pulignano V and Doerflinger N (2013) A head with two tales: trade unions' influence on temporary agency work in Belgian and German workplaces. International Journal of Human Resource Management 24(22): 4149-4165.

Pulignano V and Doerflinger N (2018a) Expanding social actor-based explanations in labour market dualisation research: A combined macro-micro and micro-macro approach. Employee Relations 40(1): 75-88.

Pulignano V and Doerflinger N (2018b) Labour markets, solidarity and precarious work: Comparing local unions' responses to management flexibility strategies in the German and Belgian metalworking and chemical industries. In Doellgast V, Lillie $\mathrm{N}$ and Pulignano $\mathrm{P}$ (eds.) Reconstructing Solidarity. Labour Unions, Precarious Work, and the Politics of Institutional Change in Europe. Oxford: Oxford University Press, 104-123.

Rodgers G (1989) Precarious work in Western Europe. The state of the debate. In Rodgers G and Rodgers J (eds.) Precarious jobs in labour market regulation. Geneva: International Labour Organisation, 1-16.

Rubery J (1978) Structured labour markets, worker organisation and low pay. Cambridge Journal of Economics 2(1): 17-36.

Rubery J (2007) Developing segmentation theory: a thirty years perspective. Economies et Societés 41(6): 941-964.

Rubery J and Fagan C (1995) Comparative industrial relations research: towards reversing the gender bias. British Journal of Industrial Relations 33(2): 209-236.

Rubery J, Keizer A and Grimshaw D (2016) Flexibility bites back: the multiple and hidden costs of flexible employment policies. Human Resource Management Journal 26(3): 235-251.

Rubery J and Piasna A (2016) Labour market segmentation and the EU reform agenda: developing alternatives to the mainstream. ETUI Working Paper 2016.10.

Rueda D (2014) Dualization, crisis and the welfare state. Socio-Economic Review 12(2): 381-407.

Russo G and Hassink W (2005) The part-time wage penalty: a career perspective. IZA Discussion Paper No. 1468.

Southwood KE (1974) Goodman and Kruskal's Tau-b as Correlation Ratio: Some implications. Sociological Methods \& Research 3(1): 82-110.

Stone K and Arthurs H (eds) (2013) Rethinking workplace regulation: Beyond the standard contract of employment. New York: Russell Sage.

Stuart M, Fagan C and Rubery J (1998) Where and why is part-time work growing in Europe? In O'Reilly J and Fagan C (eds.) Part-time prospects: an international comparison of part-time work in Europe, North America and the Pacific Rim. London: Routledge, 35-56.

Thelen K (2014) Varieties of liberalization and the new politics of social solidarity. Cambridge: Cambridge University Press.

Tilly C (1998) Durable inequality. Berkeley: University of California Press. 
Vermunt J (2010) Latent class modeling with covariates: two improved three-step approaches. Political Analysis 18(4): 450-469.

Weil D (2014) The fissured workplace: why work became so bad for so many and what can be done to improve it. Boston: Harvard University Press.

Yoon Y and Chung H (2016) New forms of dualization? Labour market segmentation patterns in the UK from the late 1990s until the post crisis in the late 2000s. Social Indicators Research 128(2): 609-631. 
Table 1: Operationalization of insecurity

\begin{tabular}{|c|c|c|}
\hline Item & Values & Concept \\
\hline \multicolumn{3}{|l|}{ Measurement model } \\
\hline Working hours & Full-time / Part-time & Temporal insecurity \\
\hline Contract type & Permanent / Temporary & Temporal insecurity \\
\hline $\begin{array}{l}\text { Supervisory } \\
\text { responsibilities }\end{array}$ & Yes / No & Organizational insecurity \\
\hline $\begin{array}{l}\text { Monthly pay from main } \\
\text { job }\end{array}$ & $\begin{array}{l}\text { Low (lowest four deciles) / Medium } \\
\text { (middle three deciles) / High (highest } \\
\text { four deciles) }\end{array}$ & Economic insecurity \\
\hline \multicolumn{3}{|l|}{ External variables } \\
\hline Gender & Male / Female & \\
\hline Age & $17-32 / 33-50 / 51-70$ & \\
\hline Nationality & $\begin{array}{c}\text { Country national / EU-national / Non- } \\
\text { EU-national }\end{array}$ & \\
\hline Education level & Low / Medium / High & \\
\hline $\begin{array}{l}\text { Occupation according to } \\
\text { ISCO-codes }\end{array}$ & $\begin{array}{c}\text { Armed forces / Managers / } \\
\text { Professionals / } \\
\text { Technicians and associate } \\
\text { professionals / } \\
\text { Clerical support workers / Service and } \\
\text { sales workers / Skilled agricultural, } \\
\text { forestry workers / Craft and trades } \\
\text { workers / Plant, machine operators, and } \\
\text { assemblers / } \\
\text { Elementary occupations }\end{array}$ & Organizational insecurity \\
\hline $\begin{array}{l}\text { Sector according to } \\
\text { NACE-codes }\end{array}$ & $\begin{array}{c}\text { Agriculture \& mining / Care services / } \\
\text { Industry \& manufacturing / Other } \\
\text { services / } \\
\text { Private services / Public administration }\end{array}$ & \\
\hline Firm size & $\begin{array}{l}\text { Small (1-10 staff) / Medium (11-49 staff) } \\
\text { / Large (50 or more staff) }\end{array}$ & \\
\hline $\begin{array}{l}\text { Existence of a second } \\
\text { job }\end{array}$ & Yes / No & Economic insecurity \\
\hline
\end{tabular}


Table 2: Profiles of the identified labour market segments*

\begin{tabular}{|c|c|c|c|c|c|}
\hline & $\begin{array}{l}\text { Standard } \\
\text { workers } 1\end{array}$ & $\begin{array}{l}\text { Standard } \\
\text { workers } 2\end{array}$ & Managers & $\begin{array}{l}\text { Part-time } \\
\text { workers }\end{array}$ & Temps \\
\hline Group size & $12 \%$ & $31 \%$ & $27 \%$ & $26 \%$ & $4 \%$ \\
\hline \multicolumn{6}{|l|}{ INDICATORS } \\
\hline \multicolumn{6}{|l|}{ Contract type } \\
\hline Permanent & $96 \%$ & $91 \%$ & $97 \%$ & $82 \%$ & $1 \%$ \\
\hline Temporary & $4 \%$ & $9 \%$ & $3 \%$ & $18 \%$ & $99 \%$ \\
\hline \multicolumn{6}{|l|}{ Working hours } \\
\hline Full-time & $97 \%$ & $79 \%$ & $97 \%$ & $31 \%$ & $100 \%$ \\
\hline Part-time & $3 \%$ & $21 \%$ & $3 \%$ & $69 \%$ & $0 \%$ \\
\hline \multicolumn{6}{|l|}{$\begin{array}{l}\text { Supervisory } \\
\text { responsibilities }\end{array}$} \\
\hline No & $100 \%$ & $78 \%$ & $39 \%$ & $91 \%$ & $98 \%$ \\
\hline Yes & $0 \%$ & $22 \%$ & $61 \%$ & $9 \%$ & $2 \%$ \\
\hline \multicolumn{6}{|l|}{ Wages } \\
\hline Low & $2 \%$ & $2 \%$ & $1 \%$ & $99 \%$ & $81 \%$ \\
\hline Middle & $59 \%$ & $85 \%$ & $16 \%$ & $1 \%$ & $18 \%$ \\
\hline High & $39 \%$ & $13 \%$ & $82 \%$ & $0 \%$ & $1 \%$ \\
\hline \multicolumn{6}{|c|}{ EXTERNAL VARIABLES } \\
\hline \multicolumn{6}{|c|}{ Gender } \\
\hline Male & $69 \%$ & $45 \%$ & $78 \%$ & $26 \%$ & $68 \%$ \\
\hline Female & $31 \%$ & $55 \%$ & $22 \%$ & $74 \%$ & $32 \%$ \\
\hline \multicolumn{6}{|l|}{ Age category } \\
\hline 1 (17-32 years) & $14 \%$ & $35 \%$ & $14 \%$ & $33 \%$ & $98 \%$ \\
\hline 2 (33-50 years) & $53 \%$ & $35 \%$ & $46 \%$ & $37 \%$ & $2 \%$ \\
\hline 3 (51-70 years) & $34 \%$ & $30 \%$ & $40 \%$ & $30 \%$ & $0 \%$ \\
\hline \multicolumn{6}{|l|}{ Education level } \\
\hline Low & $46 \%$ & $9 \%$ & $2 \%$ & $30 \%$ & $57 \%$ \\
\hline Medium & $49 \%$ & $71 \%$ & $40 \%$ & $59 \%$ & $35 \%$ \\
\hline High & $5 \%$ & $20 \%$ & $58 \%$ & $11 \%$ & $7 \%$ \\
\hline \multicolumn{6}{|l|}{ Nationality } \\
\hline Country national & $89 \%$ & $91 \%$ & $96 \%$ & $82 \%$ & $88 \%$ \\
\hline EU-national & $3 \%$ & $5 \%$ & $3 \%$ & $7 \%$ & $5 \%$ \\
\hline Non-EU-national & $8 \%$ & $4 \%$ & $1 \%$ & $11 \%$ & $7 \%$ \\
\hline \multicolumn{6}{|l|}{ SECTOR } \\
\hline $\begin{array}{l}\text { Agriculture \& } \\
\text { mining }\end{array}$ & $2 \%$ & $1 \%$ & $1 \%$ & $2 \%$ & $7 \%$ \\
\hline Care services & $6 \%$ & $16 \%$ & $8 \%$ & $15 \%$ & $12 \%$ \\
\hline $\begin{array}{l}\text { Industry \& } \\
\text { manufacturing }\end{array}$ & $42 \%$ & $27 \%$ & $35 \%$ & $14 \%$ & $36 \%$ \\
\hline Other services & $3 \%$ & $4 \%$ & $2 \%$ & $13 \%$ & $2 \%$ \\
\hline Private services & $29 \%$ & $38 \%$ & $33 \%$ & $47 \%$ & $34 \%$ \\
\hline $\begin{array}{l}\text { Public } \\
\text { administration }\end{array}$ & $19 \%$ & $15 \%$ & $22 \%$ & $9 \%$ & $9 \%$ \\
\hline \multicolumn{6}{|l|}{ Firm size } \\
\hline $\begin{array}{l}\text { Large (50 workers } \\
\text { or more) }\end{array}$ & $32 \%$ & $49 \%$ & $71 \%$ & $24 \%$ & $47 \%$ \\
\hline $\begin{array}{l}\text { Medium (11-49 } \\
\text { workers) }\end{array}$ & $41 \%$ & $33 \%$ & $23 \%$ & $33 \%$ & $36 \%$ \\
\hline $\begin{array}{l}\text { Small (1-10 } \\
\text { workers) }\end{array}$ & $27 \%$ & $18 \%$ & $6 \%$ & $43 \%$ & $17 \%$ \\
\hline \multicolumn{6}{|l|}{ Second job } \\
\hline No & $100 \%$ & $95 \%$ & $96 \%$ & $96 \%$ & $99 \%$ \\
\hline Yes & $0 \%$ & $5 \%$ & $4 \%$ & $4 \%$ & $1 \%$ \\
\hline
\end{tabular}

* Latent profile probabilities; numbers are rounded 
Table 3: Occupational profile of the identified segments *

\begin{tabular}{|l|c|c|c|c|c|}
\hline Label & $\begin{array}{l}\text { Standard } \\
\text { workers 1 }\end{array}$ & $\begin{array}{l}\text { Standard } \\
\text { workers } \\
\mathbf{2}\end{array}$ & Managers & $\begin{array}{l}\text { Part-time } \\
\text { workers }\end{array}$ & Temps \\
\hline Group size & $12 \%$ & $31 \%$ & $27 \%$ & $26 \%$ & $4 \%$ \\
\hline Occupations & & & & & \\
\hline Armed forces & $29 \%$ & $2 \%$ & $\mathbf{6 2} \%$ & $2 \%$ & $4 \%$ \\
\hline Managers & $0 \%$ & $7 \%$ & $\mathbf{8 9} \%$ & $4 \%$ & $0 \%$ \\
\hline Professionals & $8 \%$ & $26 \%$ & $\mathbf{5 5 \%}$ & $9 \%$ & $1 \%$ \\
\hline $\begin{array}{l}\text { Technicians and associate } \\
\text { professionals }\end{array}$ & $11 \%$ & $\mathbf{3 6 \%}$ & $35 \%$ & $15 \%$ & $3 \%$ \\
\hline Clerical support workers & $21 \%$ & $\mathbf{3 8 \%}$ & $12 \%$ & $27 \%$ & $3 \%$ \\
\hline Service and sales workers & $11 \%$ & $28 \%$ & $6 \%$ & $\mathbf{5 1 \%}$ & $4 \%$ \\
\hline $\begin{array}{l}\text { Skilled agricultural, forestry } \\
\text { workers }\end{array}$ & $11 \%$ & $\mathbf{3 7 \%}$ & $7 \%$ & $30 \%$ & $15 \%$ \\
\hline Craft and trades workers & $29 \%$ & $\mathbf{3 6 \%}$ & $12 \%$ & $16 \%$ & $7 \%$ \\
\hline $\begin{array}{l}\text { Plant, machine operators, and } \\
\text { assemblers }\end{array}$ & $\mathbf{3 7 \%}$ & $33 \%$ & $10 \%$ & $17 \%$ & $3 \%$ \\
\hline Elementary occupations & $13 \%$ & $20 \%$ & $1 \%$ & $\mathbf{6 2 \%}$ & $4 \%$ \\
\hline
\end{tabular}

* Latent profile probabilities adding up in rows to 100\%; numbers are rounded 
Figure 1: Group sizes per country

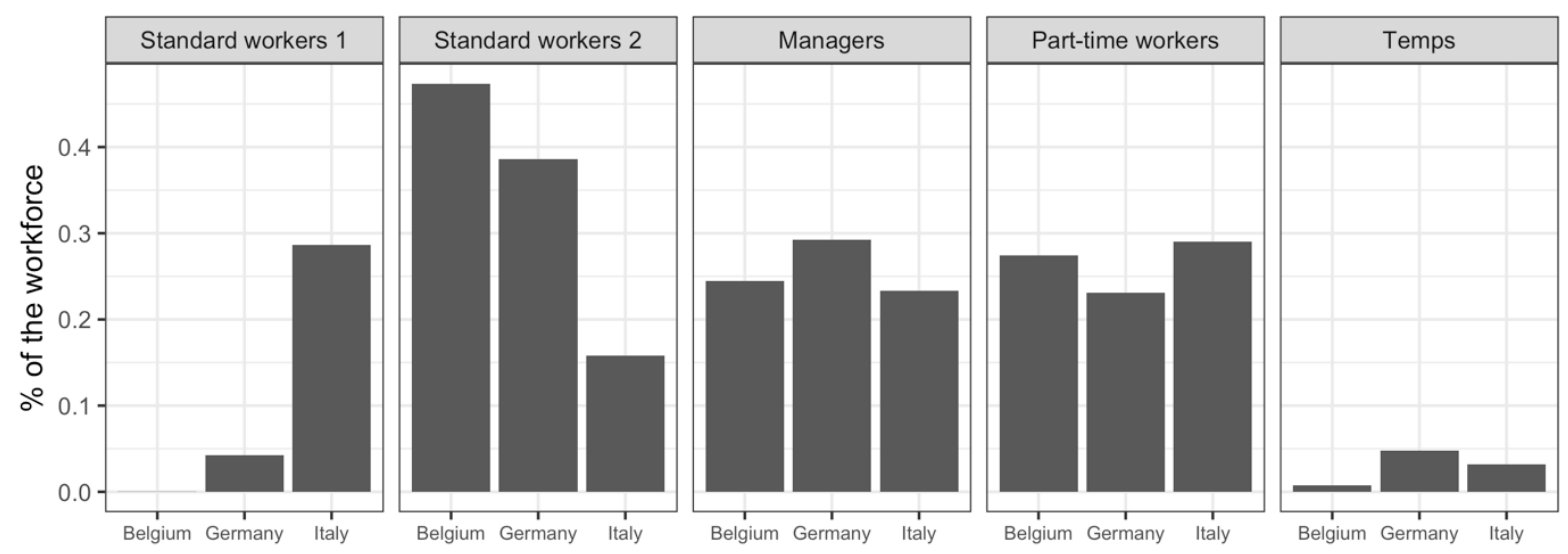


Table 4: $R^{2}$-values (rounded)

\begin{tabular}{|l|l|c|c|c|c|}
\hline & Variable & $\begin{array}{c}\mathbf{R}^{2} \\
\text { pooled }\end{array}$ & $\begin{array}{c}\mathbf{R}^{\mathbf{2}} \\
\text { Germany }\end{array}$ & $\begin{array}{c}\mathbf{R}^{\mathbf{2}} \\
\text { Belgium }\end{array}$ & $\begin{array}{c}\mathbf{R}^{\mathbf{2}} \\
\text { Italy }\end{array}$ \\
\hline Indicators & Wages & 0.64 & 0.67 & 0.68 & 0.59 \\
\cline { 2 - 6 } & Working hours & 0.39 & 0.40 & 0.34 & 0.40 \\
\cline { 2 - 6 } & Contract type & 0.31 & 0.37 & 0.11 & 0.26 \\
\cline { 2 - 6 } & $\begin{array}{l}\text { Supervisory } \\
\text { responsibilities }\end{array}$ & 0.27 & 0.24 & 0.18 & 0.36 \\
\hline
\end{tabular}




\section{Funding}

This research was developed in the framework of two interlinked research projects entiled "How are social divides produced in contemporary European labour markets?", financed by the Flemish Research Council FWO (project number G071716N) and a KU Leuven C1 grant (number C14/16/015).

\section{Biographical notes}

Nadja Doerflinger is a Postdoctoral Researcher in the Research Group "Employment Relations and Labour Markets" at the Centre for Sociological Research (CeSO), KU Leuven, Belgium. Her research especially focuses on contingent work, labour market segmentation and fragmentation, and flexibility and security in European labour markets.

Valeria Pulignano is a Professor in Sociology of Labour and Industrial Relations and Head of the Research Group "Employment Relations and Labour Markets" at the Centre for Sociological Research (CeSO), KU Leuven, Belgium. She has published extensively on comparative employment and industrial relations and labour markets in Europe.

Martin Lukac is a $\mathrm{PhD}$-student at the Centre for Sociological Research at KU Leuven. As computational social scientist, his research focuses on the intersection between labour sociology and social research methods. He works predominantly on latent variable models and using computational tools to model complex social dynamics and social networks. 